\title{
Benefit Evaluation Model for Gamified Add- Ons in Business Software
}

\section{Ferenc Erdős ${ }^{1}$ and Gábor Kallós ${ }^{2}$}

${ }^{1}$ Department of Information Technology, Faculty of Engineering Sciences, Széchenyi István University, Győr, Hungary, e-mail: erdosf@sze.hu

${ }^{2}$ Department of Mathematics and Computational Sciences, Faculty of Engineering Sciences, Széchenyi István University, Győr, Hungary, e-mail: kallos@sze.hu

Abstract: Return on IT investment analysis has become a fundamental task of the finance function at corporations, let it be large multinational organizations or small and medium businesses (SME). Besides the cost analysis, the benefit analysis is also an essential component of economic calculations and decisions. Due to complicated profit calculations and estimation methods, the benefit of IT investments is less easily forecast and hence less frequently calculated than their costs. This study focuses on a special innovative type of IT investments, the gamified extensions of business software. Gamification, which refers to the use of game design elements in a non-gaming context, can expect big development in the field of business applications in the near future. Gamification features of business software generally enhance user experience, enabling people to do otherwise boring tasks. In the following we attempt to propose a sophisticated benefit evaluation model based on the hedonic wage model (HWM) and technology acceptance model (TAM) for this special type of IT projects.

\section{Gamified Environment for Business Software}

Almost everybody likes to play. It sounds a little bit common place, but in business life it has had an increasing role recently. According to Gartner's estimate by 2014 roughly $70 \%$ of the largest enterprises ${ }^{1}$ will use different game techniques for at least one business process [11]. Today business processes are mostly supported by business software applications, hence, these types of software will be the main target of gamification projects. Gamification refers to the use of game design elements for a non-gaming context [8], [9].

Forbes Global 2000: an annual ranking of the top 2000 public companies in the world by Forbes magazine 
In the field of learning gamification is a well-tried and tested feature [16], [25], and well used since video games are frequent in the market [12], [19]. Employees interact and learn in a gamified environment, but they don't always know they are really learning. They collect scores, badges to get places on leaderboards while more knowledge is gained and shared. One of the best-known examples of gamified learning is Ribbon Hero from Microsoft to educate users of Microsoft Office 2007 and 2010 how to use the ribbon interface [32]. Using games, leisure and serious to enhance and support learning has become known as game-based learning [19].

The opportunities of gamification for businesses are great - from having more engaged customers, to enable innovation or to motivate employees in work. In this study we emphasize the last one in the field of business software and highlight personal productivity driving business results.

Economists and business theorists have been considering the case for years that companies would be much more prosperous if they allocated and influenced human resources within their organizations using different methods [22], [26]. One of these concepts is to increase personal satisfaction at work connected to human resources management, therefore, happy employees are more productive, more loyal and far more motivated to do extra efforts for their employer. Gamification of human resource can be interpreted as a new approach in this field.

\section{Benefits of Gamification Features}

Despite the promising opportunities of game elements' adoption into serious contexts such as business software, theoretical models for the financial analysis are missing. In the past few years there have been many studies available about the elements [8], [9], [17], [20], the steps [33] and the general benefits [18] of gamification projects. In the following we attempt to measure monetary benefits of gamification add-ons implemented in different business software.

Essential types of gamification features of business applications generally enhance user experience, enable people to do otherwise boring tasks so that there is a visual design and other incentive substance using game design techniques.

Despite their great potential to advance efficiency throughout the company, gamifying of business software requires grounded managerial thought and consideration before they are implemented within an organization. Besides the clear declaration of gamification project goals, an adequate cost-benefit analysis is necessary with a thorough cause-effect breakdown. In this study we intend to provide only an ex-ante benefit evaluation model, nevertheless a total cost of ownership (TCO) calculation is an essential task besides benefit estimation. After the implementation from time to time an ex-post analysis of the effectiveness of the gamification project is very important too. 
The monetary measurement of such benefits is very complicated because this feature raises efficiency by intangible qualitative factors. The incidental improvement of employee's performance is very hard to anticipate and measure, so the yields of such projects are vague.

Working from the principle that enhanced user experience shifts user activities towards higher value added activity, we provide a sophisticated procedure, which is a modification of Sassone's Hedonic Wage Model (HWM) [23].

\section{HWM-based Evaluation}

The hedonistic model, or labor value procedure can be interpreted as a TSTS (Time Savings Times Salary) model's extension [15], although the related basic idea of the method was applied in connection with the change in price research already in the 1930's [13]. HWM is based on the statement that labor resources of a company can be allocated with certain economic criteria. Every employee carries out different types of work related tasks, and these activities bring different values for the enterprise [24].

The original basis of this methodology is the hedonic equation in which the prices of different product models are the dependent variables and the characteristics of the product types are the independent variables. The basic conceptual model is to determine the price of goods that can be offered only in different composite shopping baskets. In this situation consumers have to consider the benefits of each individual good before they buy. [13]

For the use of the HVM evaluation model for gamification features in business software it is necessary to record and evaluate the relevant changes within the spectrum of the work processes owing to the gamification add-ons. The essence of our methodology is to identify all users where gamification features will be used, categorize tasks of these users and determine the proportion of time spent with these tasks as a percentage of total working hours.

At first, we have to determine the user groups $(i=1, \ldots, I)$ with the same activities, and the number of user group members $\left(L_{i}\right.$, in $i^{\text {th }}$ group) which are affected by the new gamified interface. If the intended application of gamification elements is optional for the users, the proportion that will use this feature $\left(P_{i}\right.$, in $i^{\text {th }}$ group) has to be estimated for every user group. In our estimation the obligatory usage of gamification could be unproductive for a part of users.

Then we have to establish the different activities $(j=1, \ldots, J)$ of the users. Furthermore, we have to determine for all user groups the time spent with each activity in proportion to total working time calculated. Based on these, the data analyzed can be presented in a so-called activity-profile matrix, which is denoted by $M=\left(m_{i j}\right)$. Accordingly, $m_{i j}$ denotes the office hours of activity " $j$ " in proportion 
to the total working hours by user group " $i$ ". In addition, the average hourly wages of each user group $\left(C_{i}\right)$ need to be taken into account.

\subsection{Maximizing Problem}

For the solution of the maximizing problem we use the Lagrange method as Sassone did in his original hedonic wage model [23].

Assuming that the interested Reader is familiar with the Lagrange method for solving conditional extremum problems, we omit here the detailed presentation.

We note shortly that in practical economics, the modification of the classic extremum problem in the following way, is a common exercise: the domain of the original function $(f)$ is restricted/constrained to special places (given by a function $g)$.

The formal goal of the procedure is to determine the local extremum with function $L$ - which no longer has outside conditions - defined by the equation

$$
\begin{gathered}
L\left(x_{1}, x_{2}, \ldots, x_{n}, \lambda_{1}, \lambda_{2}, \ldots, \lambda_{m}\right)=f\left(x_{1}, x_{2}, \ldots, x_{n}\right)+ \\
+\sum_{j=1}^{m} \lambda_{j} g_{j}\left(x_{1}, x_{2}, \ldots, x_{n}\right) .
\end{gathered}
$$

If from the setting of the problem the existence of the extremum follows, the equation system

$$
\frac{\partial}{\partial x_{i}}\left(f+\sum_{j=1}^{m} \lambda_{j} g_{j}\right)(\underline{a})=0 \text { and } g_{j}(\underline{a})=0
$$

(with $i \in\{1,2, \ldots, n\}, j \in\{1,2, \ldots, m\}$ ) consists of $n+m$ equations and $n+m$ unknown variables $x_{1}, x_{2}, \ldots, x_{n}, \lambda_{1}, \lambda_{2}, \ldots, \lambda_{m}$ and this system has only one solution, then its place is given by the first $n$ components of the solution (the unknown variables $\lambda_{1}, \lambda_{2}, \ldots, \lambda_{m}$ can be eliminated from the equation system without determining their values [4], [21]).

\subsection{The Proposed Gamified Model}

The economic criterion is to maximize the profit of the company under the circumstances of technical and economic constraints. The profit of the company $(\pi)$ is the difference between revenues and costs, that is $\pi=R-C$.

Let's consider the short-run profit-maximization problem when inputs are fixed at some level, so we cannot change the amount of factors of production. In other words, there is a budget constraint for the wage costs of the affected employees in short term: 


$$
B \geq \sum_{i=1}^{I} C_{i} \cdot L_{i} \cdot P_{i}
$$

To project the economic criterion for this problem, we have to maximize the profit from the work of the users, who use gamification features of a business application:

$$
R\left(\sum_{i=1}^{I} m_{i 1} \cdot L_{i} \cdot P_{i}, \ldots, \sum_{i=1}^{I} m_{i J} \cdot L_{i} \cdot P_{i}\right)-\sum_{i=1}^{I} C_{i} \cdot L_{i} \cdot P_{i} \rightarrow \max
$$

From (3) we can create the following constraint equation for the maximizing problem (4), in the form required for the Lagrange method:

$$
\sum_{i=1}^{I} C_{i} \cdot L_{i} \cdot P_{i}-B=0
$$

For the simplicity we introduce variable $L P_{i}$, which is the number of users in user group " $i$ ", which is intended to use the gamification software mechanics.

$$
L P_{i}=L_{i} \cdot P_{i}
$$

From parts (4) and (5) we can build the Lagrange function $(L f)$ :

$$
\begin{gathered}
L f\left(L P_{1}, \ldots, L P_{I}, \lambda\right)=R\left(\sum_{i=1}^{I} m_{i 1} \cdot L P_{i}, \ldots, \sum_{i=1}^{I} m_{i j} \cdot L P_{i}\right)-\left(\sum_{i=1}^{I} C_{i} \cdot L P_{i}\right)+ \\
+\lambda \cdot\left(B-\sum_{i=1}^{I} C_{i} \cdot L P_{i}\right) \\
L f\left(L P_{1}, \ldots, L P_{I}, \lambda\right)=R\left(\sum_{i=1}^{I} m_{i 1} \cdot L P_{i}, \ldots, \sum_{i=1}^{I} m_{i j} \cdot L P_{i}\right)- \\
-(1+\lambda)\left(\sum_{i=1}^{I} C_{i} \cdot L P_{i}\right)+\lambda \cdot B
\end{gathered}
$$

From the Lagrange function (7) we can build the $i^{\text {th }}$ piece partial derivative equations.

$$
\begin{gathered}
\frac{\partial L F}{\partial L P_{i}}=\sum_{j=1}^{J} \frac{\partial R}{\partial L P_{i}} \cdot m_{i j}-(1+\lambda) \cdot C_{i}=0 \quad \text { for } i=1 \text { to } I \\
\sum_{j=1}^{J} V M P A_{j} \cdot m_{i j}=(1+\lambda) \cdot C_{i} \quad \text { for } i=1 \text { to } I
\end{gathered}
$$


$\mathrm{VMPA}_{j}$ describes the value of marginal product of the activity " $j$ " of the employees from different groups, which are involved in the use of gamification features.

Every " $i$ " (10) equation described on the left side is the weighted sum of the marginal product of the actual user groups' activities. On the right the average labor cost of the user group " $i$ " is based on the assumption that the Lagrange multiplier is zero $(\lambda=0)$, so the marginal opportunity costs for the employment of user group " $i$ " members are equal to the direct costs of the user group " $i$ ". According to this statement, the actual number of gamification users in different groups is optimal within the organization.

The " $i$ " (10) equations build up a system of linear equations with $J$ unknown marginal values. Starting from the fact that one of the $J$ activities is an unproductive activity, which has zero marginal value $\left(\mathrm{VMPA}_{J}=0\right), J-1$ equations (user groups) are needed to solve the system of linear equations. These values of marginal product of activities (from $\mathrm{VMPA}_{1}$ to $\mathrm{VMPA}_{J}$ ) represent the implicit unit labor cost for each activity.

\section{TAM-based Prediction}

The technology acceptance model, originally proposed by Davis [5], is a model to explain and predict the use of a system. The model is based on the theory of reasoned action (TRA) by Ajzen and Fishbein [1]. According to this model the use of an IT system can be explained or predicted by user's motivation, which is directly influenced by the features of system. Perceived usefulness and perceived ease of use are supposed to influence attitudes toward new technology and mediate the relationship between external variables and attitude [7].

As stated by Davis, perceived usefulness is the degree to which an individual believes that using a particular system would enhance his or her job performance and perceived ease of use is the degree to which an individual believes that using a particular system would be free of physical and mental effort [5].

Latter versions of TAM realized that behavioral intention as a further variable would be directly influenced by the perceived usefulness ant the perceived ease of use of a system [6], [27]. Davis and Venkatesh [28] have extended the model to TAM2 and introduced three interrelated social factors: subjective norm, voluntariness and image. 


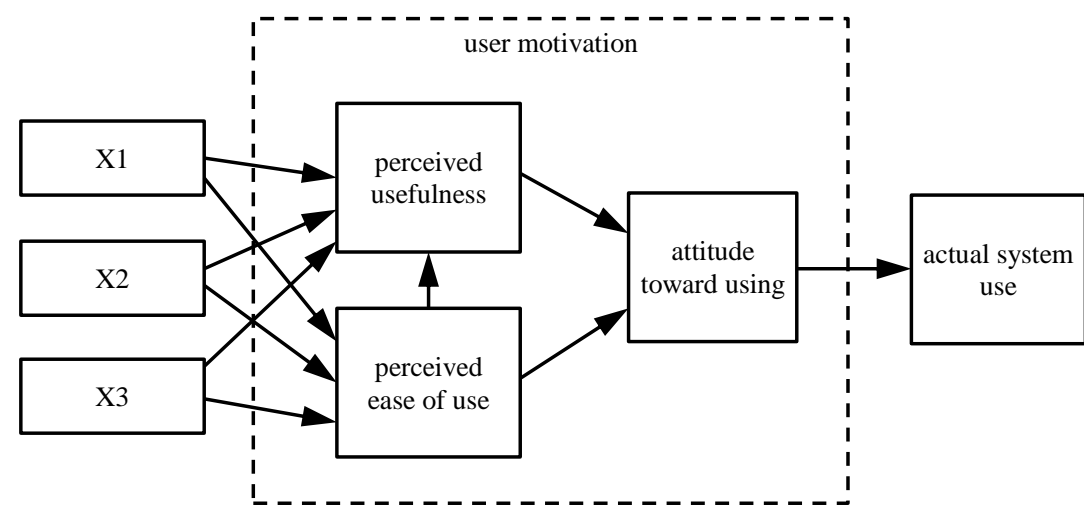

Figure 1

Original conceptual model for technology acceptance (Davis, 1986, p. 24)

The main goal of different technology acceptance models is to study how individual user perceptions affect the intentions to use information technology and further the actual usage as illustrated in Figure 2.

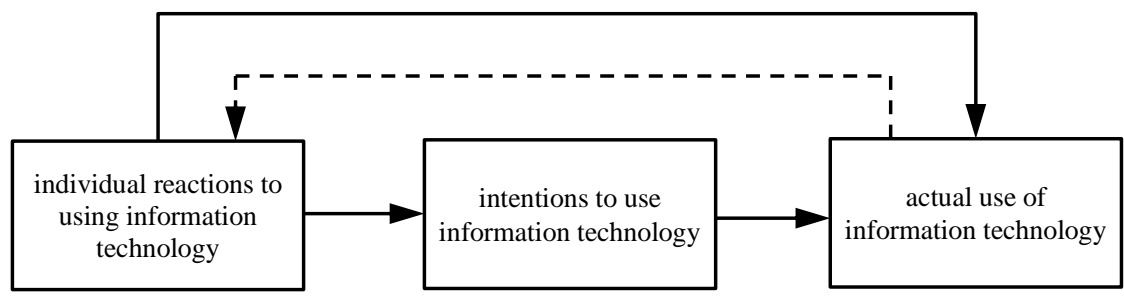

Figure 2

Basic concept of different technology acceptance models (Venkatesh et al., 2003)

To evaluate gamification add-ons in different business software we have combined the original TAM with other user acceptance research approaches and extended it with special factors. In the following we intend to use this model to forecast user acceptance of gamified business applications. We propose some external variables to predict the behavioral intention as a consequence of gamified software environment. The main goal is to forecast the changes within the spectrum of the work processes. 


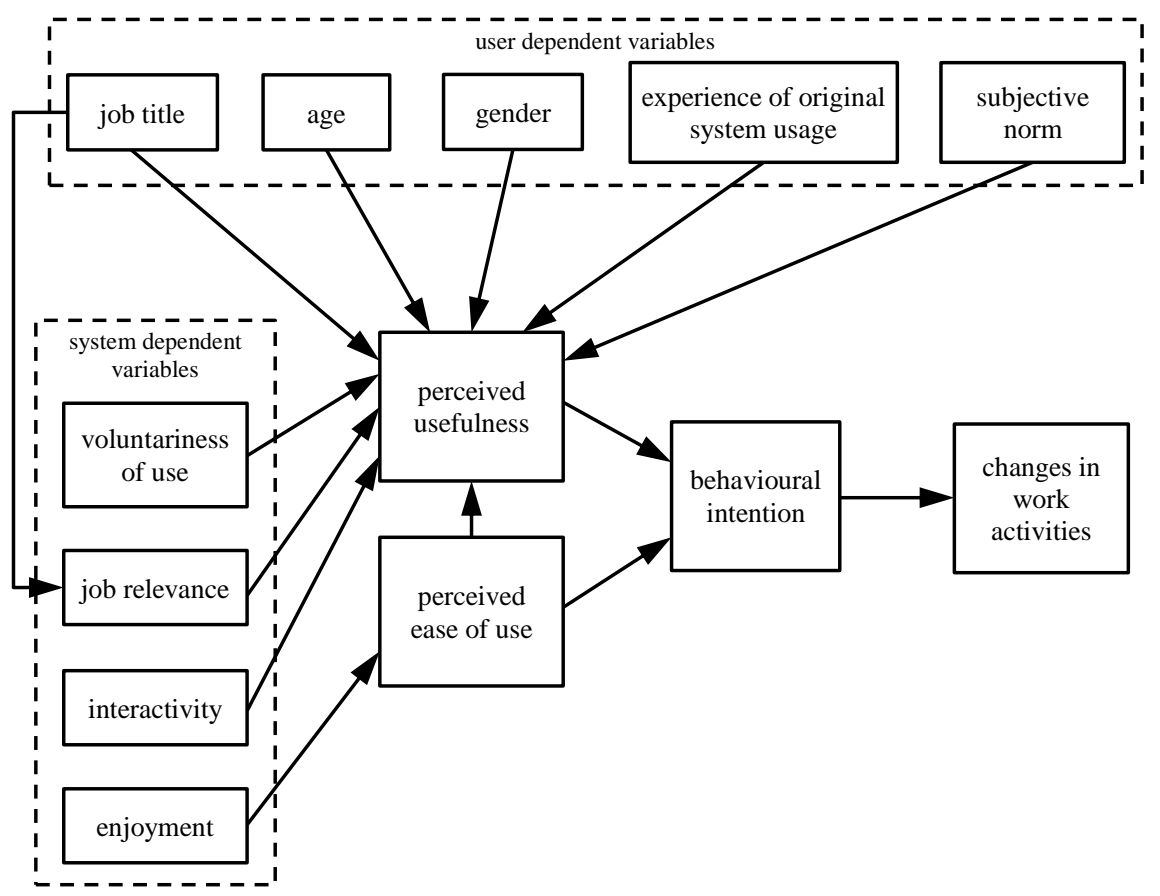

Figure 3

Model of gamification features use in business applications based on the technology acceptance model

The above described model assumes that functionality is identical between the original GUI and gamified solution. According to our theory it is necessary to estimate the relevance of different variables regarding to perceived usefulness and perceived easy to use. To evolve measurement scales for these two main motivation factors psychometric scales used in psychology can be used. The relevance of each variable is different due to the distinctive gamification solution and user characteristics. The significance analyses before implementation should be studied with real users and actual usage situations. The user sample has to contain employees from different user groups and has to be representative. The aim is to find significant factors that influence behavioral intention and the changes in work activities. Different descriptive statistical methods (such as mean, standard deviation, frequency and correlation) are available to determine significance of factors based on user's responses.

If a user regards the perceived usefulness or the perceived ease of use of the gamified software interface worse than the original GUI, it is necessary to enable the usage of the original one to avoid ineffectiveness and unproductiveness.

The next step is to estimate the new activity-profile matrix $\left(N=\left(n_{i j}\right)\right)$ with the help of TAM as a result of the gamification implementation. It is necessary to forecast for all user groups the modified time spent with each " $j$ " activity in 
proportion to total working time. According to our model, the increased user experience shifts the user activities towards higher value added activities in different degree, according to the variables of TAM. So we have to consider these factors for every employees of the user group and estimate the average new proportion of different activities, which can be used to estimate benefits extracted after applying gamification add-ons. The modified activity-profile matrix must reflect the increased efficiency as a result of gamified software environment.

The final step is to compare the original $\left(M=\left(m_{i j}\right)\right)$ and the new $\left(N=\left(n_{i j}\right)\right)$ activity-profile matrices and the activity increases or decreases have to be calculated for every user group. Using the values of marginal product of different “ $j$ " activities $\left(\mathrm{VMPA}_{j}\right)$ and the shift of activities $\left(N-M=\left(n_{i j}-m_{i j}\right)\right)$, financial benefit can be calculated for an employee of every user group and for an optional time period. The total benefit of gamification ownership (TBGO) is the summarized value of these calculations multiplied with the total of working hours of different user groups $\left(t_{i}\right)$ projected for the whole investigated period and for the number of users in user group " $i$ ", which intended to use the gamification software elements $\left(L P_{i}\right)$.

$$
T B G O=\sum_{i=1}^{I}\left(\sum_{j=1}^{J}\left(V M P A_{j} \cdot\left(n_{i j}-m_{i j}\right) \cdot t_{i}\right) \cdot L P_{i}\right)
$$

For instance on the basis of a 40-hour work week and 48-week active work year for user group " $i$ ", a 3-year horizon calculation " $t_{i}$ " equals 5,760 office hours.

\section{Application Example}

In the following - based on the work of Sassone [23] - we present a possible application of our model. During the building up of the application example our goal was to endow several systems working in the academic sphere (management information systems - MIS, document management system, education system and other office systems) with gamification features and to report of the achieved financial benefit of efficiency grows. To the creation of the activity profile matrix the data source was our workplace, Széchenyi István University.

The activities (scopes of the duties) were selected in a way that in the daily routine substantial differences should exist among the categories. We have distinguished one leader (head/full professor), one senior lecturer (associate professor, professor assistant), one demonstrator and one administrator position (4 groups). We took interviews with some colleagues in the groups, and averaging the answers an activity net was worked up (with common activities for the groups). During the configuration we used some reasonable simplifications in order to have a not too complicated descriptive matrix. 
The leaders/full professors e.g. gave the following main activities: management or control/leadership (projects, industrial connections, discussions, meetings, coordination of department or institute), correspondence (with other leaders, professors, researchers), study and research (conferences, reading and writing papers), lessons and their preparation, administration (document management, mailing, education administration). We divided these complicated scopes of activities into 4 main parts according to the possible application for the other user groups. However, it is clear that the meaning of "study and research" can be very different for an administrator or for a lecturer. Since the different activity groups can have intersections, too (e.g. mailing - correspondence), we made "finetuning" among the categories. Moreover, for all employee types it can be detected that a part of the working time is useless (non-productive). It was added as a separate activity. So, for our case e.g. the activity profile of a leader/full professor is as follows: management - 36\%, study and research $-19 \%$, lessons and preparation $-15 \%$, mailing and administration $-20 \%$. Table 1 shows the recorded activity profile of all user groups.

After it we gave an estimation for the cost of the employment of the workers (hourly rate; here besides the wages we have planed the fringe benefits and additional costs). The value of the Lagrange-multiplicator was chosen to 0 (which means in the practice that there is no unnecessary capacity). The costs in our example are 24, 20.5, 18 and 14 monetary units, respectively.

Table 1

Recorded activity profile of users before the application of gamification techniques

\begin{tabular}{|c|c|c|c|c|c|c|c|}
\hline & \multicolumn{5}{|c|}{ Activities } & \multirow{2}{*}{$\begin{array}{c}\text { Hourly } \\
\text { rate }\end{array}$} \\
\hline & & $\begin{array}{c}\text { Manage/ } \\
\text { Project }\end{array}$ & $\begin{array}{l}\text { Study/ } \\
\text { Research }\end{array}$ & $\begin{array}{c}\text { Lessons/ } \\
\text { Prep. }\end{array}$ & Admin. & Non-prod. & \\
\hline \multirow{4}{*}{ 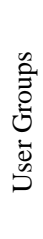 } & $\begin{array}{l}\text { Head/ } \\
\text { Professor }\end{array}$ & 0.36 & 0.19 & 0.15 & 0.2 & 0.1 & 24 \\
\hline & $\begin{array}{c}\text { Assoc./ } \\
\text { Assist.Prof. }\end{array}$ & 0.15 & 0.25 & 0.25 & 0.24 & 0.11 & 20.5 \\
\hline & Demonstrator & 0.02 & 0.18 & 0.51 & 0.15 & 0.14 & 18 \\
\hline & Administrator & 0.07 & 0.02 & 0 & 0.74 & 0.17 & 14 \\
\hline
\end{tabular}

Omitting the non-productive activities we get a square matrix (activities and duties/profiles; here: our goal was to search a unique solution). In the next step we solve the equation system with the inverse matrix method, so we get the pure marginal value of the different activities (produced value in 1 hour; in our example: $36.5,25.3,20.6$ and 14.8 monetary units, respectively).

The unit value of each activity - as written above - is, of course, an oversimplification of the real situation. The value of study/research in many cases cannot be measured directly - how can we calculate e.g. the research impasse? The experience can be very valuable... The result, however, correlates well with 
the practical expectations, on average, the most valuable "unit price" of the management work e.g. can conveniently justify with the great obtainable benefit.

For the time being we could only estimate the change available with the introduction of the gamification add-ons, since the gamification-TAM model presented in Figure 3 was not yet validated. There are here several such uncertainties which can be built up correctly only with a longer tracking - among them immediately the one, that how many percent of the staff will be susceptible to the new structure.

The goal is clear - with the increase of the employee's satisfaction and acceptance - increased efficiency, which means partly the quicker/faster completion of a given task, on the other hand the possible execution of more value added tasks during a specific period of time, so we expect that the activities of the workers shift towards the most valuable activity categories.

If, for example, we can make the time spent with monotonic administration friendlier with a simultaneous running of a gamification application (e.g. kinder user interface, amusing effects, funny praises, collecting points and badges, setting goals), then the given task can be done partly more efficiently, partly in a less tiring (more amusing) way. The time saved (or a part of it) can be used for study/research, or so the colleague can undertake a greater "slice" from the project works.

Taking into account all of these factors we can estimate the financial yield of the increased efficiency.

We recorded the original profile and the calculated/estimated profile of a given employee-group (in our case now: associate professor/professor assistant; columns $\mathrm{B}$ and D in Table 2.). Assuming 40 hour working time (weekly) we determined the time required (weekly) for each activity (columns C and E). The efficiencygrow (in percent) is mostly an estimation (column F). After it we calculated the new performance of the colleague working with larger efficiency which now exceeds 40 hours (in our example: 41.15 hours; column G). Finally, we calculated the annual benefit (column $\mathrm{J}$ ), based on the unit price of the activities, taking into account 45 working weeks annually. Concerning one associate professor/professor assistant, we have annually 2058 monetary units benefit.

Table 2

Benefit calculation for associate professors and professor assistants

\begin{tabular}{|c|c|c|c|c|c|c|c|c|c|}
\hline 4 & $B$ & c & D & $E$ & $F$ & G & $\mathrm{H}$ & 1 & $\mathrm{k}$ \\
\hline 19 & Benefit for Assoo & c/Assist Prof & & & & & & & \\
\hline 20 & Activity & Init profile & Init hours & Final profile & Final hours & Proj increase & Equiv hours & Orig marg values & Annual new values \\
\hline 21 & Manage/project & 0.15 & 6 & 0.16 & 6.4 & 2 & 6.53 & 36.52 & 867.62 \\
\hline 22 & Study/research & 0.25 & 10 & 0.27 & 10.8 & 1 & 10.91 & 25.32 & 1034.75 \\
\hline 23 & Lessons/prep & 0.25 & 10 & 0.25 & 10 & 3 & 10.3 & 20.58 & 277.79 \\
\hline 24 & Admin & 0.24 & 9.6 & 0.22 & 8.8 & 7 & 9.42 & 14.78 & -122.38 \\
\hline 25 & Non-prod & 0.11 & 4.4 & 0.1 & 4 & 0 & 4 & 0 & 0 \\
\hline 26 & Total & 1.00 & 40.00 & 1.00 & 40.00 & & 41.15 & & 2057.8 \\
\hline
\end{tabular}


We can observe that there will be such an activity where the objective function results negative values (here: administration), this naturally, does not diminish the benefit in total.

Similarly, we made this tabular for all worker groups (so we had 4 intermediate objective/cost functions). Finally, we recorded the data of a specific department (the number of the employees in each group) and the 4 intermediate cost functions -weighted properly- were combined in a final objective function (here: cell H45).

Table 3

Total benefit calculation of gamified software environment

\begin{tabular}{|c|c|c|c|c|c|c|c|c|c|}
\hline \multicolumn{2}{|r|}{$\mathrm{H} 45$} & \multirow{2}{*}{$\frac{C}{\mathrm{~B}}$} & \multirow[t]{2}{*}{$f_{x}$} & \multicolumn{6}{|c|}{$=D 45^{*} J 16+F 45^{*} J 25+D 46^{*} J 34+F 46^{*} J 43$} \\
\hline 4 & A & & & C & D & E & $\mathrm{F}$ & G & $\mathrm{H}$ \\
\hline \multicolumn{10}{|l|}{44} \\
\hline 45 & \multicolumn{2}{|c|}{ Number of colleagues } & \multicolumn{2}{|c|}{ Head/Prof } & \multicolumn{2}{|r|}{2 Assoc/Assist Prof } & & 5 Objective function & 42559 \\
\hline 46 & & & Den & honstrator & & 14 Administrator & & 2 & (Benefit) \\
\hline
\end{tabular}

In the following, our goal was to examine the summarized financial effect of the gamification features with a probability forecast. To the forecast we used a MonteCarlo simulation. This simulation technique is a generally accepted scientific tool to handle the risks resulting in uncertainty, the point of which is that based on the probability distribution assigned to each uncertainty factor we choose randomly values which are used in the experiments of the simulation [30].

The formal goal is to determine the expected value

$$
\psi=E_{\varphi}[f(X)]=\int f(x) \varphi(x) d x
$$

where $X$ is a real-valued random variable with probability density $\varphi$, and $f$ is a real-valued function. Since density $\varphi$ is common unknown or too complicated, we estimate $\Psi$ using randomly chosen $f\left(x_{i}\right)$ points. (The empirical mean obtained this way tends to the real integral value indeed in closed intervals.)

In our case

$$
\psi=E_{\varphi}[T B G O(X)]=\int T B G O(x) \varphi(x) d x
$$

and

$$
\widehat{\psi}=\frac{1}{n}\left(T B G O\left(x_{1}\right)+T B G O\left(x_{2}\right)+\cdots+T B G O\left(x_{n}\right)\right),
$$

where $n$ is the number of experiments ( $n$ is large). Thus, increasing the number of experiments the distribution of total benefit of gamification ownership function arbitrary accuracy can be specified [14], [31].

In the gamification model to be analyzed, we fixed the estimated changed activity profile matrix as influential variables, and their possible intervals, respectively. In the probability distribution of the influential variables we used normal 
distribution, but the value of the deviation was defined so that about $90 \%$ of the data should fit in the interval [mean - deviation, mean + deviation], not $68 \%$, as usual. During the simulation, the values of the variables (in given intervals and with given distribution) were produced by a random number generator. Altogether we made 10000 experiments with computer aided Monte-Carlo simulation.

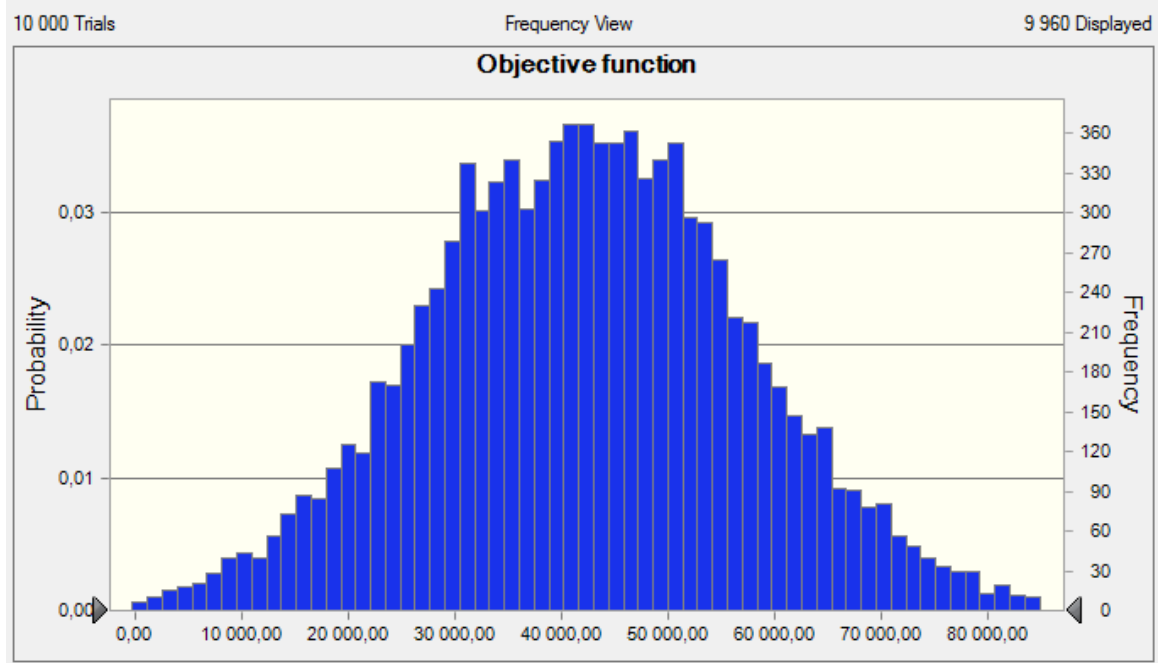

Figure 4

Probability forecast of gamification's total financial effect

Running the simulation we got the histogram (Figure 4) which suits "value by weight" well our prior expectations. The expected benefit falls with a very large probability in the interval $[25000,60000]$ monetary units. The chart serves with a little surprise anyway: our matrix is very sensitive even for small changes, so in several places the curve seems to be oddly deficient. We see too, that several extreme cases were not shown by the program (40 cases from the 10000).

\section{Conclusions}

In this study we proposed a complete procedure that facilitates the benefit calculations of gamification projects in the field of business applications. Based on the hedonic wage model and technology acceptance model, we defined a set of methods that allowed us to quantify the ex-ante, mid-term and ex-post financial measurement of such investments projects. The practical application of our framework needs significant and thorough estimation, examination and calculation efforts to get an adequate and real yield analysis.

\section{References}

[1] Ajzen, I., Fishbein, M.: Understanding Attitudes and Predicting Social Behaviour, Prentice Hall, Englewood Cliffs, NJ, p. 278 (1980) 
[2] Aparicio, A. F., Vela, F. L. G., Sánchez, J. L. G., Montes, J. L. I.: INTERACCION '12: Proceedings of the $13^{\text {th }}$ International Conference on Interacción Persona-Ordenador, Article No. 17 (2012)

[3] Bernhaupt, R.: Evaluating User Experience in Games: Concepts and methods, Springer, London, p. 286 (2010)

[4] Bertsekas, D. P.: Nonlinear Programming (Second Ed.), Athena Scientific Publ., Cambridge, MA, p. 777 (1999)

[5] Davis, F. D.: A Technology Acceptance Model for Empirically Testing New End-User Information Systems: Theory and Results, Doctoral dissertation, MIT Sloan School of Management, Cambridge, MA, p. 291 (1985)

[6] Davis, F. D., Bagozzi, R. P., Warshaw, P. R.: User Acceptance of Computer Technology: a Comparison of Two Theoretical Models, Management Science 35(8), pp. 982-1003 (1989)

[7] Davis, F. D., Venkatesh, V.: A Critical Assessment of Potential Measurement Biases in the Technology Acceptance Model: Three Experiments. International Journal of Human-Computer Studies, 45(1), pp. 19-45 (1986)

[8] Deterding, S., Dixon, D., Khaled, R., Nacke, L.: From Game Design Elements to Gamefulness: Defining "Gamification". Proceedings from MindTrek'11 (ACM), Tampere, Finland, pp. 9-15 (2011)

[9] Deterding, S., Sicart, M., Nacke, L., O’Hara, K., Dixon, D.: Gamification: Using Game Design Elements in Non-Gaming Contexts, Paper presented at CHI 2011, Vancouver, Canada, pp. 2425-2428 (2011)

[10] Erdős, F.: Different Techniques to Quantify the Yield of IT Projects, SEFBIS Journal 7, pp. 11-17 (2012)

[11] Gartner: Gartner Enterprise Architecture Summit 2011 - Press Release, Egham, UK, April 12, 2011, http://www.gartner.com/newsroom/id/1629214 Retrieved 3 March 2013

[12] Gee, J. P.: What Video Games Have to Teach US about Learning and Literacy, Palgrave Macmillan, New York, p. 225 (2003)

[13] Janko, W. H.: Informationswirtschaft 2 - Informationswirtschaft im Unternehmen, Wirtschaftsuniversität Wien, Wien, p. 571 (2010)

[14] Jorgensen, E.: Monte Carlo simulation models: Sampling from the Joint Distribution of "State of Nature"-Parameters, Proceedings of the Symposium on "Economic modelling of Animal Health and Farm Management", Farm Management Group, Dept. of Social Sciences, Wageningen University, pp. 73-84 (2000) 
[15] Kesten, R., Schröder, H., Wozniak, A.: Konzept zur Nutzenbewertung von IT Investitionen. Arbeitspapiere der Nordakademie 3. Nordakademie, Elmshorn, p. 39 (2006)

[16] Lee, J. J., Hammer, J.: Gamification in Education: What, How, Why Bother? Academic Exchange Quarterly, 15(2) pp. 1-5 (2011)

[17] Liu, Y., Alexandrova, T., Nakajima, T.: Gamifying Intelligent Environments, Proceedings of the 2011 international ACM workshop on Ubiquitous meta user interfaces, pp. 7-12 (2011)

[18] Pankajakshan, V., Nair, S.: When Work Becomes Play: Gamification of HR, Proceedings of Tenth AIMS International Conference on Management, pp. 1327-1333 (2013)

[19] Prensky, M.: Digital Game-based Learning, USA, McGraw-Hill, New York, p. 442 (2007)

[20] Reeves, B., Read, J. L.: Total Engagement: Using Games and Virtual Worlds to Change the Way People Work and Businesses Compete. Harvard Business Press, Boston, p. 274 (2009)

[21] Reinhard, F., Soeder, H.: Dtv-Atlas zur Mathematik, Deutscher Taschenbuch Verlag, München, p. 272 (1974)

[22] Robins, J. A.: Organizational Considerations in the Evaluation of Capital Assets: Toward a Resource-based View of Strategic Investment by Firms, Organization Science 3(4), pp. 522-536 (1992)

[23] Sassone, P. G.: Cost-Benefit Methodology for Office Systems, ACM Transactions on Office Systems 5(3), pp. 273-289 (1987)

[24] Sassone, P. G., Schwartz, A. P.: Office Information Systems Cost Justification, IEEE Aerospace and Electronic Systems Magazine, 1(8), pp. 21-26 (1986)

[25] Simões, J., Redondo, R. D., Vilas, A. F.: A Social Gamification Framework for a K-6 Learning Platform. Computers in Human Behavior, 29(2), pp. $345-353$ (2013)

[26] Suen, W., Chan, W.: Labour Market in a Dynamic Economy, Hong Kong Economic Policy Studies Series, City University of Hong Kong Press, Hong Kong (1997)

[27] Venkatesh, V., Davis, F. D.: A Model of the Antecedents of Perceived Ease of Use: Development and Test. Decision Sciences, 27(3), pp. 451-481 (1996)

[28] Venkatesh, V., Davis, F. D.: Theoretical Extension of the Technology Acceptance Model: Four longitudinal field studies, Management Science, 46(2), pp. 186-204 (2000) 
[29] Venkatesh, V., Morris, M. G., Davis, G. B., Davis, F. D.: User Acceptance of Information Technology: Toward a Unified View, MIS Quarterly, 27(3), pp. 425-478 (2003)

[30] Vose, D.: Risk Analysis, John Wiley \& Sons Ltd.: New York, p. 418 (2006)

[31] Watson, H.: Computer Simulation in Business. Whiley, New York, p. 358 (1981)

[32] Welinske, J.: Ribbon Hero - User Assistance Masquerading as a Game, Writer's UA, (2010), http://www.writersua.com/articles/ribbon_hero Retrieved 3 March 2013

[33] Werbach, K., Hunter, D.: For The Win: How Game Thinking Can Revolutionize Your Business, Wharton Digital Press, Philadelphia, p. 146 (2012) 